\title{
SHEAR STRENGTH CHARACTERISTICS OF FIBROUS SOLID WASTE MATERIALS IN LANDFILL SITES
}

\author{
M. F. Awad-Allah \\ Department of Civil Engineering, National Research Center, Cairo, Egypt.
}

\begin{abstract}
Slope-stability failures have occurred in several improper landfills and illegal dumping sites. To investigate the shear response of municipal solid waste (MSW), it is significant to consider the stability of dumping site and landfill design. In the present paper, the shear response and shear strength of MSW recovered from four different landfill sites (in Japan and China) were investigated using a developed in-situ direct shear test apparatus. Moreover, the paper introduces the steps for preparation of undisturbed samples and test procedures in details to determine the in-situ shear strength characteristics (c and $\varphi$ ) of MSW. The in-situ experimental results indicated that the shear response of waste materials affected by the existence of fibrous materials. In addition, the values of cohesion and friction parameters of waste materials strongly depended on the percent of fibrous materials. Results of geotechnical investigations and slope stability studies of landfill sites have been also introduced.
\end{abstract}

\section{KEYWORDS: Fibrous - In-situ direct shear test - Landfill - Shear strength - Waste materials.}

\section{INTRODUCTION}

Municipal solid waste (MSW) materials can be defined as any of a variety of solid materials, as well as some liquids in containers, which are discarded or rejected as being spent, useless, worthless or in excess. A large number of MSW is generated everyday around the world, and landfills have been widely constructed to dispose MSW (Dixon et al, 2005; Zhan et al, 2008; Reddyet al, 2009; and Machado et al, 2010). Recently, due to limited space in Japan, for example, the capacities of MSW landfills has been maximized by building landfill sites of greater heights with steeper slopes. This situation has raised concerns regarding the stability of high (MSW) landfills.

Instabilities of artificial landfill slopes, which mainly consist of solid waste materials, have occurred in several sites, including the Payatas landfill in Philippines (Jafari et al, 2010), Java landfill site in Indonesia (Koelsch et al. 2005), Gnojna Grora landfill in Poland (Bouzza and Wojnarowicz, 2000), Istanbul landfill in Turkey (Koerner and Soong, 2000), and Dona Junna landfill in Colombia (Hendron et al, 1999). These situations have caused significant economic and environmental consequences and, in some cases, resulted in loss of human lives. Shear strength characteristics ( $\mathrm{c}$ and $\varphi$ ) of MSW landfill materials is a function of many factors such as composition, moisture conditions, compaction, daily cover, waste type, age, decomposition, overburden pressure, etc. (Nejan and Timothy, 2008). Evaluation of shear strength parameters in landfill sites is essentially required to understand the slope failure mechanism and to evaluate the stability of various waste grounds.

The geotechnical properties of MSW are of prime importance for the design and maintenance of any type of landfill. Therefore, in previous studies, laboratory tests were mainly performed 
using specific types of wastes collected from landfill site which ignored the in-situ mechanical and physical properties of solid waste materials (Towhata, 2007, and Zekkos and Bray, 2010). Furthermore, the structure of waste materials is essentially varied from site to site. Therefore, in order to provide insight regarding the real physical and mechanical proper-ties of waste materials, in-situ geotechnical tests are definitely needed. Determination of the shear strength parameters depending on composition ratio of waste materials is important to establish an evaluation scheme of waste ground.

Consequently, in this work in-situ direct shear test apparatus was exclusively developed for testing of solid waste materials. In-situ tests were conducted on four solid waste sites that consist of different composition ratios of waste materials (two sites in Japan and two in China). Accordingly, the relationships between in-situ shear response and composition ratio of waste materials were estimated, and a method for estimating the shear strength of various waste grounds considering the content of fibrous materials was introduced.

\section{IN-SITU DIRECT SHEAR TEST SET-UP AND TEST PROCEDURE \\ 2.1. Specimen preparation}

For the purpose of measuring in-situ shear response of waste materials, a direct shear test apparatus made of steel was exclusively manufactured, as shown in Figure. 1. This test apparatus was primarily designed to be setup in-situ, and it equipped with data acquisition system. The shear displacement rate can be controlled by hydraulic jack, and meanwhile vertical and horizontal displacements are measured using two independent linear variable displacement transducers (LVDTs). Normal stress is applied either by actual weight, which becomes ten times using principle of leverage by load lever (i.e., 1:10 ratio), or by hydraulic load cell. The reaction forces generated due to loading actions can be carried via six screw anchored piles which have $220 \mathrm{~mm}$ length and diameter of $50 \mathrm{~mm}$. The shear box has internal dimensions of 300x300x 150 $\mathrm{mm}$. Preparation procedures of undisturbed specimens for direct shear test are illustrated in Figure. 2. The specimen can be prepared as follows:

(1) An open pit is excavated at the test location to the required level, and the specimen frame, which has same size as shear box $(30 \times 30 \times 15 \mathrm{~cm})$, is placed on the center of the open pit, as shown in Figure 2(a).

(2) The specimen frame is pushed downward into the ground of the tested waste martials to depth of $20 \mathrm{~cm}$, and then trimming of excess specimen is performed carefully by using grinding machine which can smoothly cut the protruded waste materials. The condition of the completed specimen in the frame is shown in Figure 2(b).

(3) The specimen is placed into the shear box after pull out the frame. The loading frame and anchoring piles are attached to shear box as shown in Figure 2(c).

(4) Finally, the data acquisition system, all measurements tools (i.e., LVDTs, load cell, etc.),

\subsection{Test procedures} and weights are attached to the test setup shown in Figure 2(d).

Series of in-situ direct shear tests has been conducted. The tests comprised of two phases including, initial compression process and then shearing process. In compression process, specimen is loaded under a certain normal stress until one of the following conditions achieved, either the measured vertical settlement becomes constant with time, or keeping constant normal load for a period of ten minutes. In a shearing process, the upper half of the shear box is displaced horizontally up to $40 \mathrm{~mm}$ under constant normal stress. In this study, the horizontal displacement rate was selected nominally to be $1 \mathrm{~mm} / \mathrm{min}$ (Miyamoto et al, 2014). In the series of direct shear test, the vertical displacement of specimen top cap, the shear displacement of upper shear box and the shear force are recorded using a digital data acquisition system. 
SHEAR STRENGTH CHARACTERISTICS OF FIBROUS SOLID WASTE MATERIALS IN LANDFILL SITES
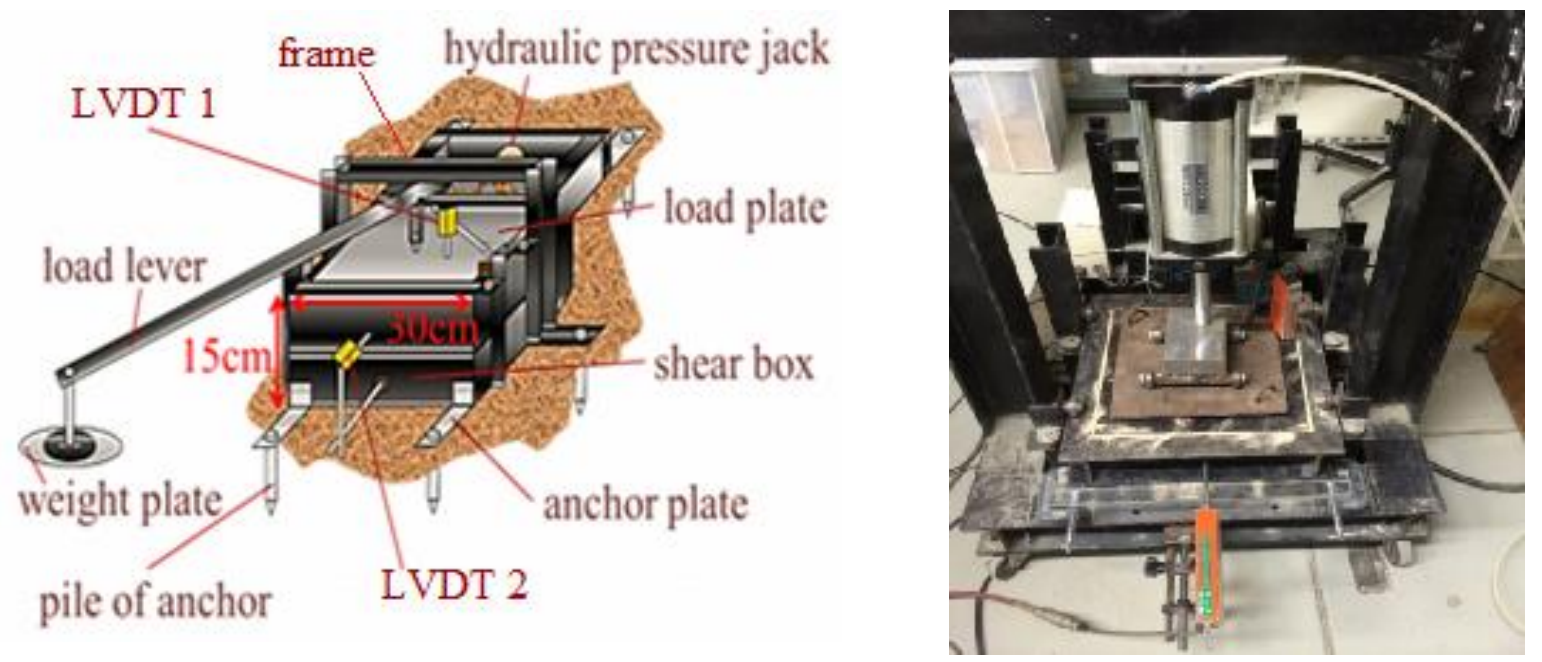

Figure 1. In-situ direct shear test apparatus.
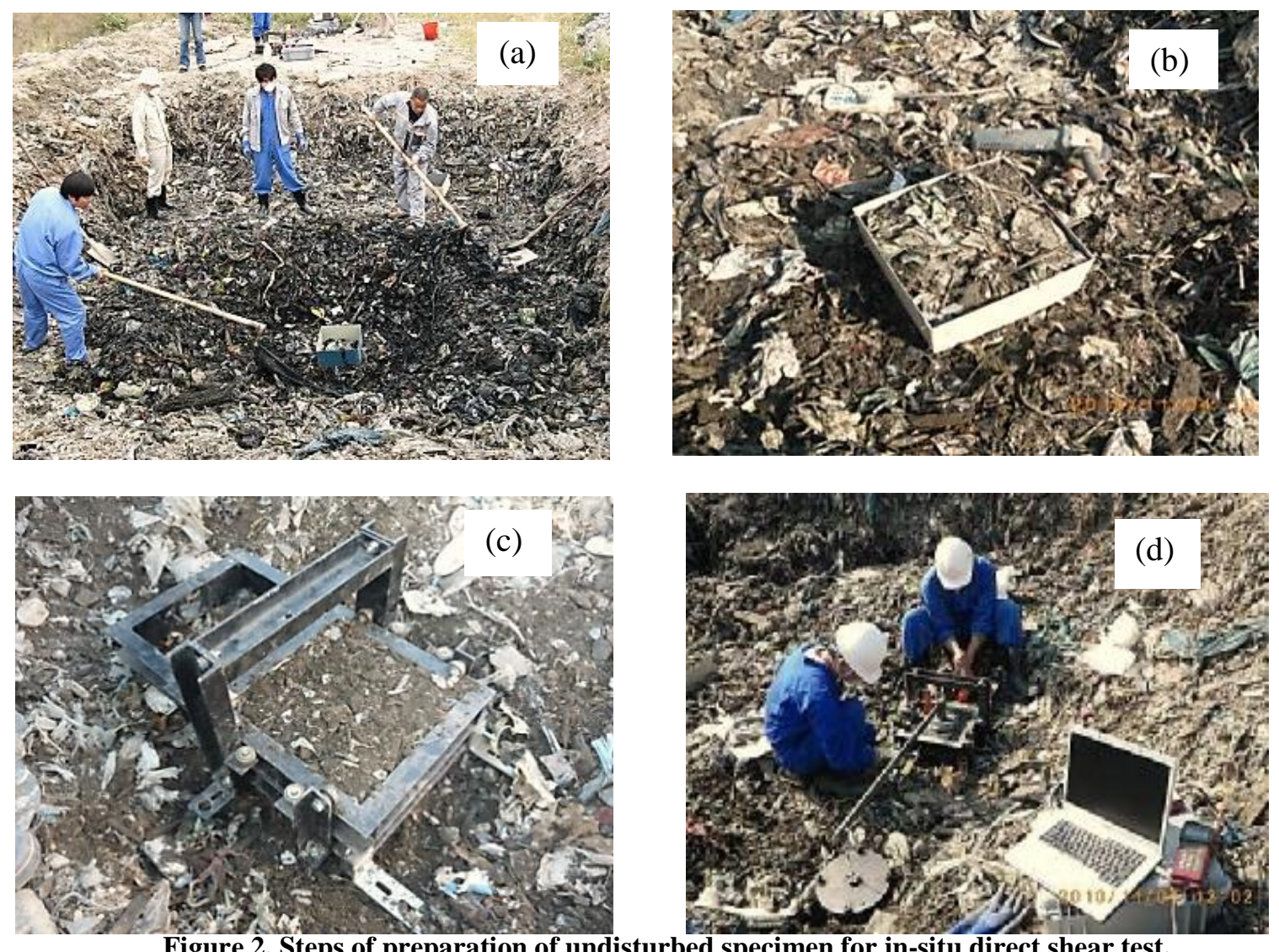

Figure 2. Steps of preparation of undisturbed specimen for in-situ direct shear test.

\section{DESCRIPTION OF LANDFILL SITES (CASE STUDIES) \\ 3.1 General}

Tables 1 and 2 summarize the general view, composition ratios, wet unit weight and water content of the four waste ground sites investigated in this study. Sites I-JAP and II-JAP are illegal dumping sites in Japan where they were made by throwing away the waste materials over 
permission capacity in intermediate treatment facilities. As steep slopes were made compulsorily, the situations in which slope instabilities are. On the other hand, sites I-CHA and II-CHA are located in china. These case studies were selected with different composition ratios of waste materials.

\subsection{Mechanical and physical properties of the waste materials}

For initial classification and inspections, samples of weight of $5 \mathrm{~kg}$ of waste materials were extracted from each site to estimate the content ratio of waste material components. In this study, the physical classification of waste materials was found to be composited of fibrous materials (mainly plastics), gravel with pottery, metal, wood, geo-materials finer $5 \mathrm{~mm}$ and others. The results show that gravel with pottery and geo-materials finer $5 \mathrm{~mm}$ are greatest content in weight. It is also clear that the content of fibrous material is varied in each site.

In-situ dry densities were examined by water replacement method for in-situ unit weight test (JGS1612, 2012), which can be applied for materials containing over than $150 \mathrm{~mm}$ particle size, and the water contents were estimated using (JIS A 1203, 2009). To contain the various shaped materials in the waste ground, this method was adopted. In comparison with general soil, the dry densities of waste materials indicate small values due to presence of high amount of low specific gravity materials such as fibrous materials. The relationships between dry unit weight and fibrous materials fraction for the four case studies are shown in Figure 3. It is obvious that the dry unit weight decreases with increasing of fibrous materials fraction.

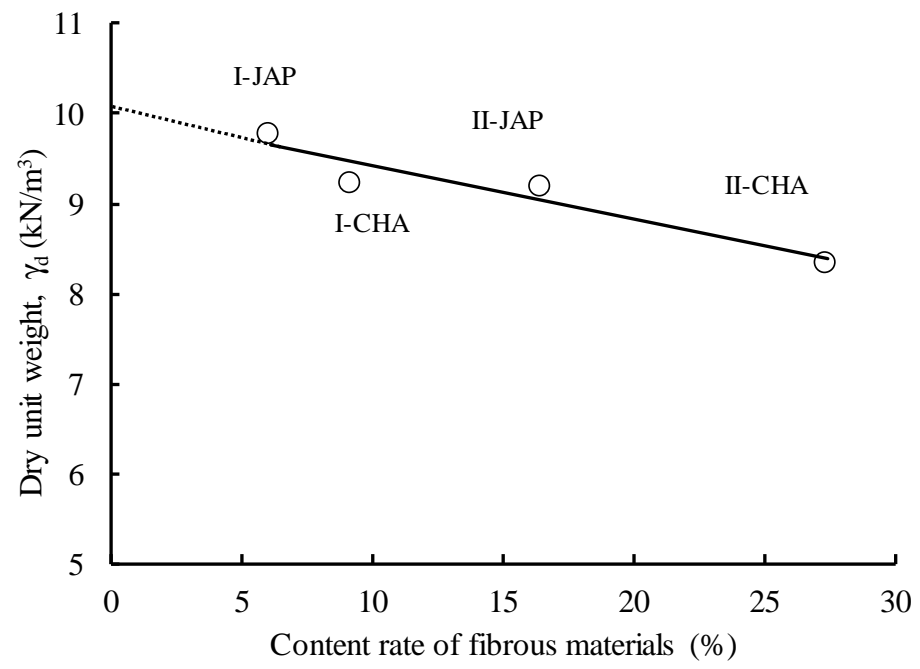

Figure 3. Dry unit weight versus fibrous materials content ratio for the four case studies. 
Table 1. Landfill characteristics of dumping sites I-JAP and II-JAP (general view, composition ratio, wet unit weight and water content).

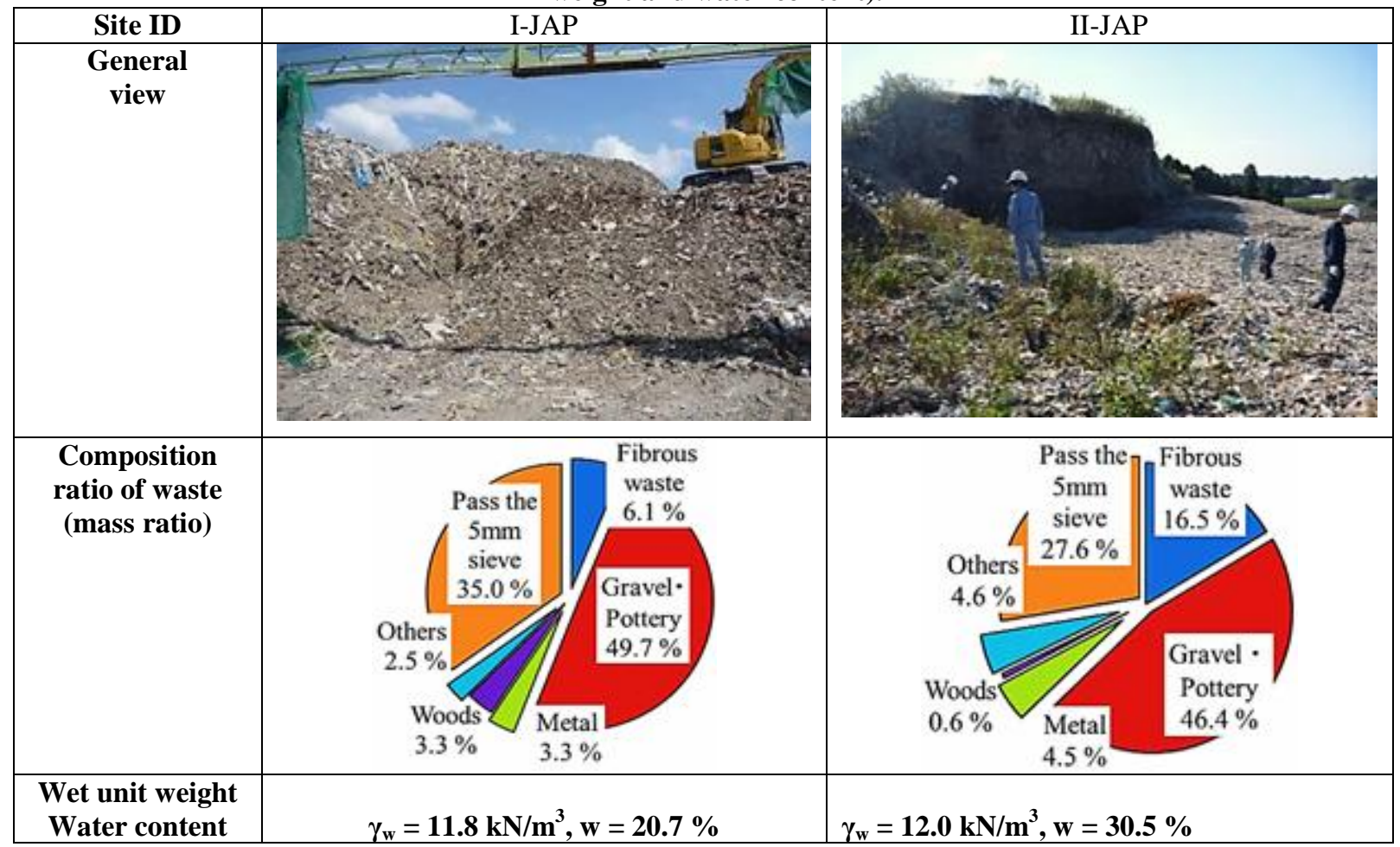

Table 2. Landfill characteristics of dumping sites I-CHA and II-CHA (general view, composition ratio, wet unit weight and water content).

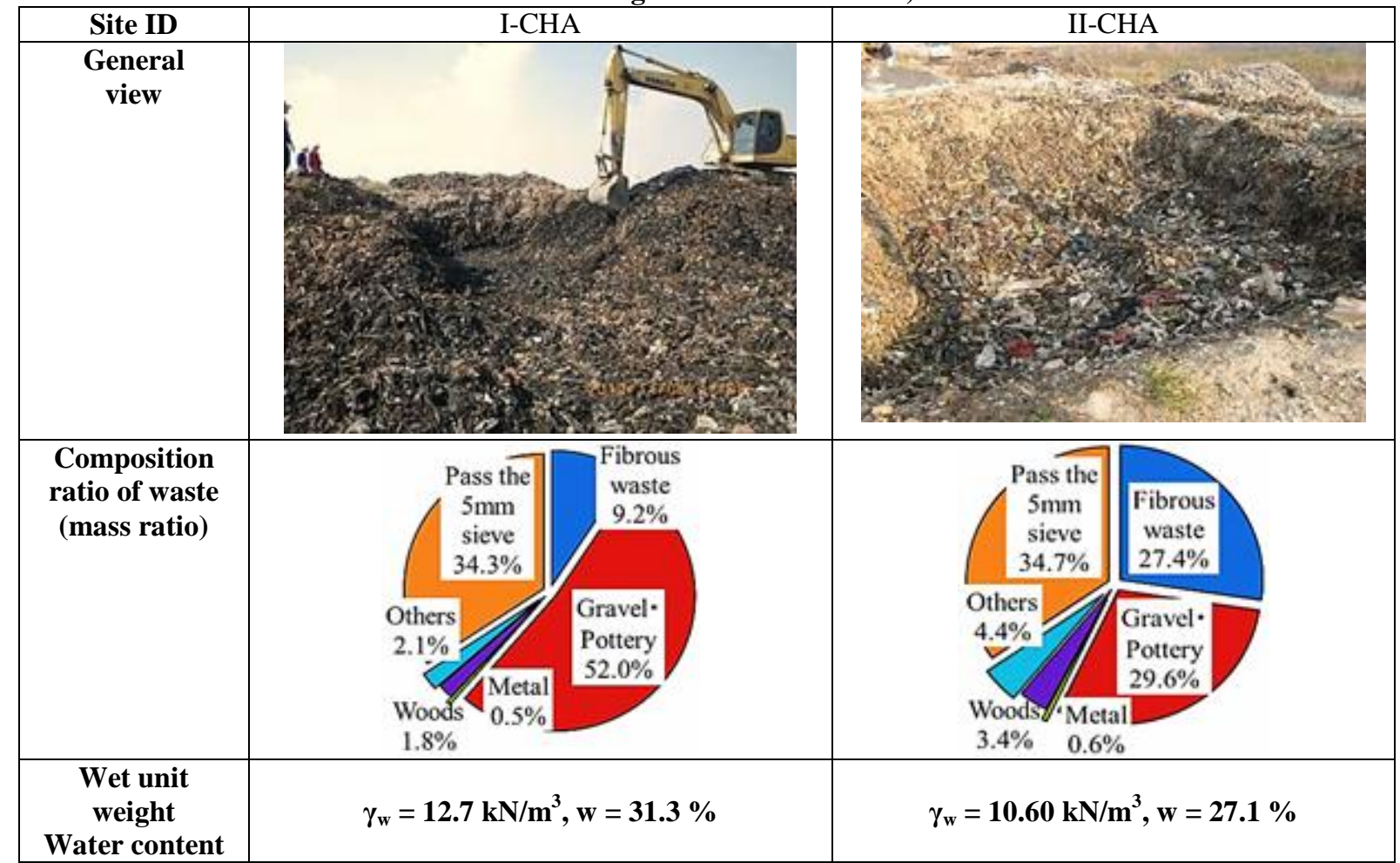



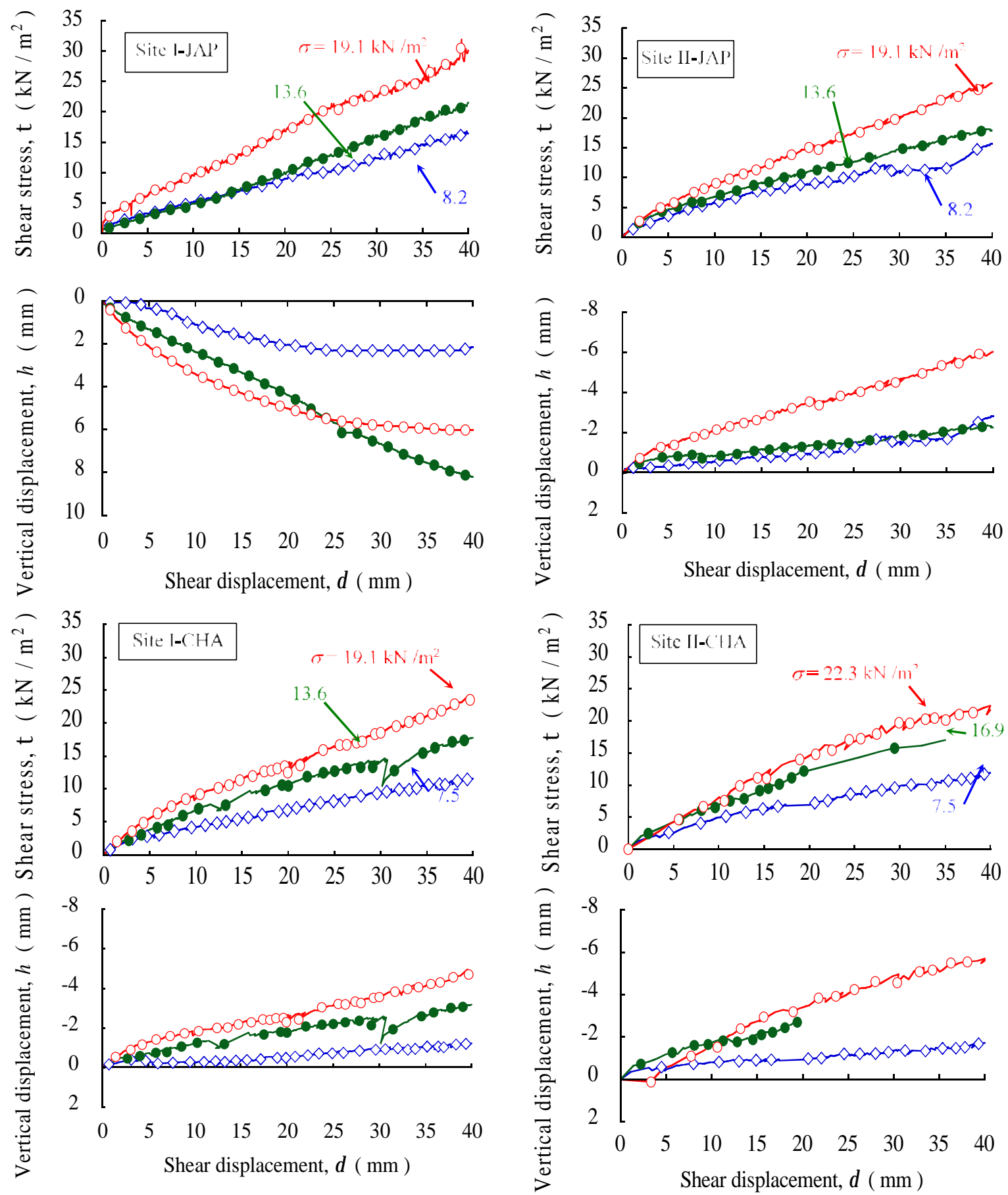

Figure 4. In-situ shear response of waste material samples collected from the four case studies.

\section{IN-SITU SHEAR RESPONSE}

Shear response of the undisturbed waste materials samples collected from the four landfill sites are depicted in Figure 4. These figures represents illustrative example of direct shear test results for only two sites. As shown in these figures, the relationships between shear stress and shear displacement, as well as the relationships between vertical displacement and shear displacement are demonstrated. It can be noted that the increase tendency of shear stresses ap- 
pears with linear hardening, but there are no clear distinct peak strengths has been observed for all results. This behavior provides evidence that the presence of fibrous materials cause reinforcement effect which in turn stretch with increasing shear deformation.

In terms of vertical displacement and shear displacement relationships, it is obvious that the difference in composition ratios of waste materials affect the deformation response at shear. The deformation characteristics of site I-JAP, which has the lowest content rate of fibrous materials (6.1\%), obviously reveals contraction behavior. On the other hand, the other landfill sites, which contain higher contents of fibrous materials, reveal expansion behavior, and this tendency becomes clear with increasing normal stress.

Furthermore, to consider the dilatancy property of waste materials, the relationships between stress ratio $(\tau / \sigma)$ and deformation ratio $(-\mathrm{dh} / \mathrm{d} \delta)$ are presented in Figure 5. As an illustrative example, the results of sites I-JAP and II-JAP are shown. It can be seen that at small stress ratio ranges, the deformation ratio of waste materials which have low content of fibrous materials increases gradually, while the waste materials which consist of high content of fibrous materials decrease with increasing stress ratio. On the other hand, at large stress ranges, deformation ratio indicates a constant value irrespective of content of fibrous materials. This behavior implies that shear response depends mainly on the amount of fibrous materials content at small deformation range, however elasticity property becomes prominent in large deformation ranges regardless of the amount of fibrous materials content due to stretching of fibrous materials with increasing shear displacement. Consequently, from above results, it is clearly found that the shear responses of waste materials show ductility and elasticity characteristics because of stretching deformation of fibrous materials during shearing.

\subsection{Definition of maximum shear strength}

In this study, shear strength of MSW tested is observed to be displacement dependent. The maximum shear strength is defined as the mobilized shear stress at a shear displacement of 35 $\mathrm{mm}$, which is the maximum displacement measured accurately by this apparatus, unless peak shear stress conditions reached at smaller shear displacement. It was observed from all results that the distinct peak strengths of waste materials have not been occurred during shearing tests. However, the relationships between mobilized secant angle and shear displacement are shown in Figure 6, which were obtained from in-situ shear response at maximum normal stress conditions in each site as shown in Figure 4.
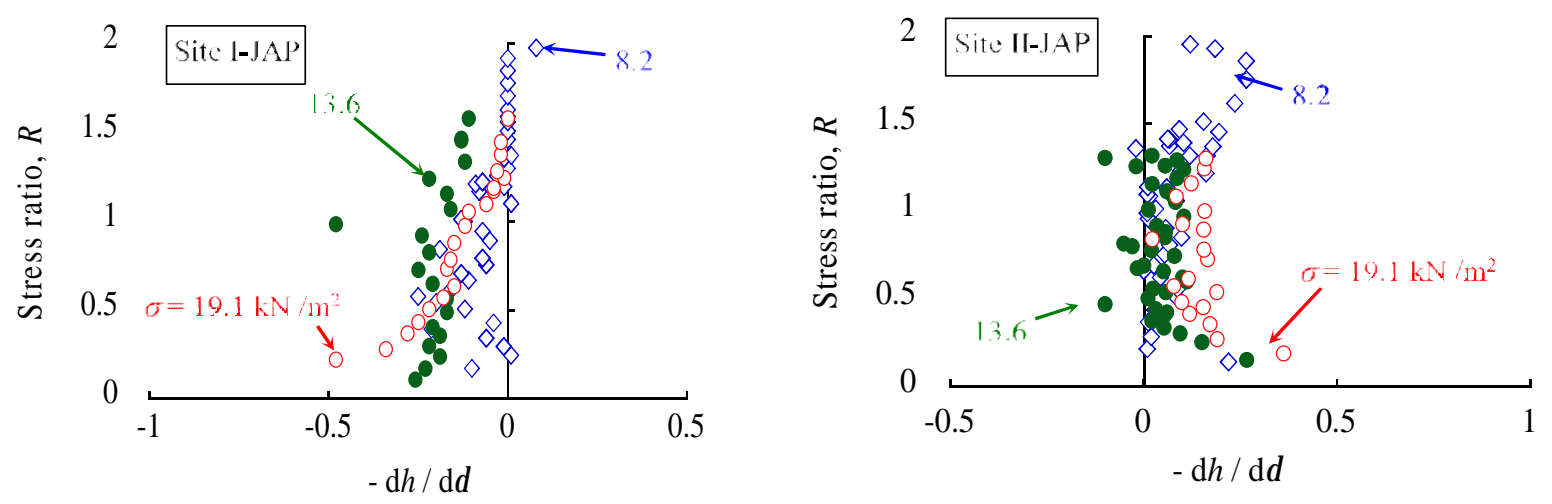

Figure 5. Dilatancy characteristics of waste materials found in landfill sites I-JAP and II-JAP. 


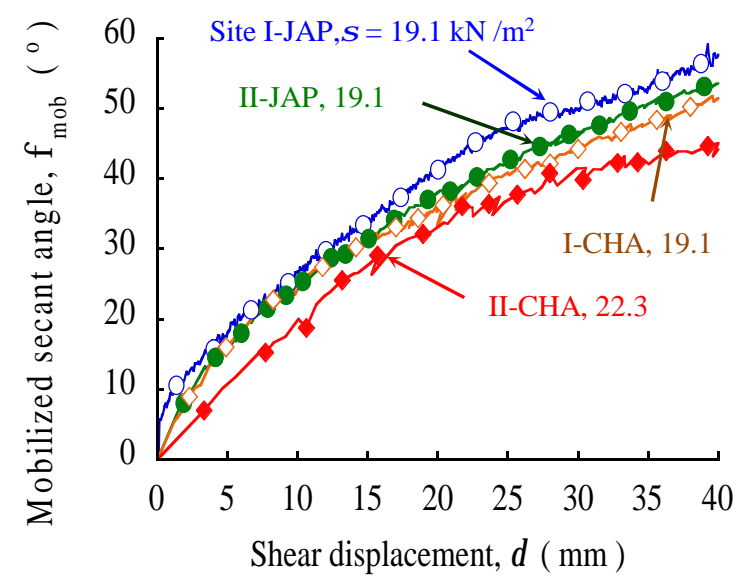

Figure 6. Mobilized secant angle versus shear displacements at maximum normal stress for all landfill sites.

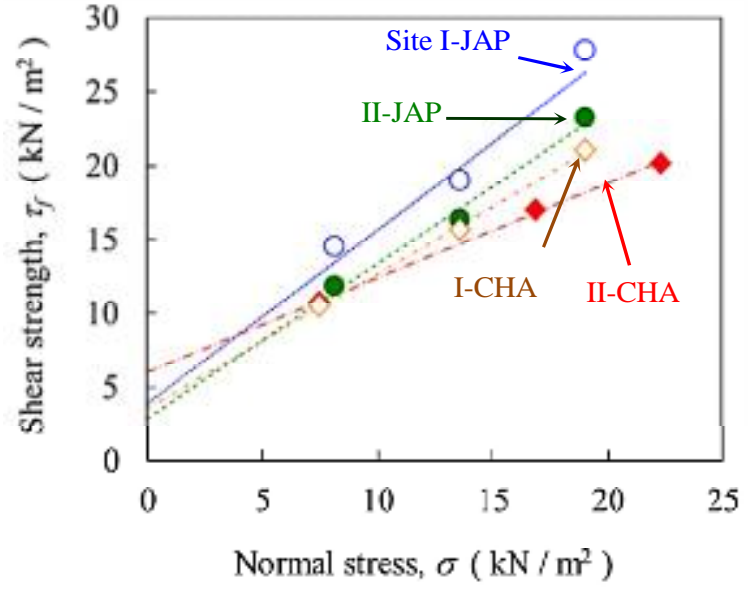

Figure 7. Shear strength and normal stress relationships for all waste materials of the landfill sites.

Table. 3. Measured in-situ shear strength of waste materials for all landfill sites.

\begin{tabular}{|c|c|c|c|c|c|}
\hline \multirow[b]{2}{*}{ Site ID } & \multirow{2}{*}{$\begin{array}{c}\text { Normal } \\
\text { stress, } \sigma \\
\left(\mathbf{k N} / \mathbf{m}^{2}\right)\end{array}$} & \multirow{2}{*}{$\begin{array}{c}\text { Shear strength, } \\
\tau_{f} \\
\left(\mathbf{k N} / \mathbf{m}^{2}\right)\end{array}$} & \multirow[b]{2}{*}{$\begin{array}{l}\text { Fibrous materials content } \\
\qquad(\%)\end{array}$} & \multicolumn{2}{|c|}{$\begin{array}{c}\text { Mobilized shear strength } \\
\text { parameters }\end{array}$} \\
\hline & & & & $\begin{array}{l}\text { Cohesion, } c \\
\left(\mathbf{k N} / \mathbf{m}^{2}\right)\end{array}$ & $\begin{array}{c}\text { Friction } \\
\text { Angle, } \phi \\
\text { ( degrees ) } \\
\end{array}$ \\
\hline I-JAP & $\begin{array}{c}8.2 \\
13.6 \\
19.1\end{array}$ & $\begin{array}{l}14.5 \\
19.0 \\
27.8\end{array}$ & 6.1 & 3.9 & 50.6 \\
\hline II-JAP & $\begin{array}{c}8.2 \\
13.6 \\
19.1\end{array}$ & $\begin{array}{l}11.8 \\
16.4 \\
23.2\end{array}$ & 16.5 & 2.9 & 46.2 \\
\hline I-CHA & $\begin{array}{c}7.5 \\
13.6 \\
19.1 \\
\end{array}$ & $\begin{array}{l}10.5 \\
15.7 \\
21.1 \\
\end{array}$ & 9.2 & 3.5 & 42.5 \\
\hline II-CHA & $\begin{array}{c}7.5 \\
16.9 \\
22.3\end{array}$ & $\begin{array}{l}10.7 \\
17.0 \\
20.2 \\
\end{array}$ & 27.4 & 6.0 & 32.6 \\
\hline
\end{tabular}

\subsection{Effect of fibrous content on shear strength parameters}

Table 3 summarize the findings of the conducted direct shear tests in terms of shear strength parameters of waste materials ( $\mathrm{c}$ and $\phi$ ). Moreover, the relationships between shear strength and normal stress of all sites are shown in Figure 7. As depicted in this figure, the mobilized shear strength parameters of waste materials ( $\mathrm{c}$ and $\phi$ ) can be easily determined using Coulomb failure criteria. Figures 8 and 9 show the relationships between cohesion and the friction angle versus the content rate of fibrous materials, respectively. It can be noted that the change in both of cohesion and friction angle of waste materials are almost constant for samples containing fibrous materials ratio of less than $15 \%$. However, for samples containing fibrous materials ratio of more than $15 \%$, cohesion value increases while friction angle value de-creases with increasing fibrous materials fraction. This result makes it clear that cohesion of waste material controls the shear behavior over than the internal friction angle. Especially, at fibrous materials fraction of approximately over than $15 \%$ is considered as boundary value of characteristic change. Accordingly, from the above finding it is obvious that the shear response and shear strength of 
various waste materials can be evaluated adequately by estimating the value of fibrous materials content.

The mobilized shear strength parameters i.e., the apparent cohesion intercept (c) and friction angle $(\phi)$ of MSW at these four dumps are best characterized by $\mathrm{c}=2.9$ to $6.0 \mathrm{kPa}$ and $\phi=32.6^{\circ}$ to $50.6^{\circ}$ at $35 \mathrm{~mm}$ lateral displacement.

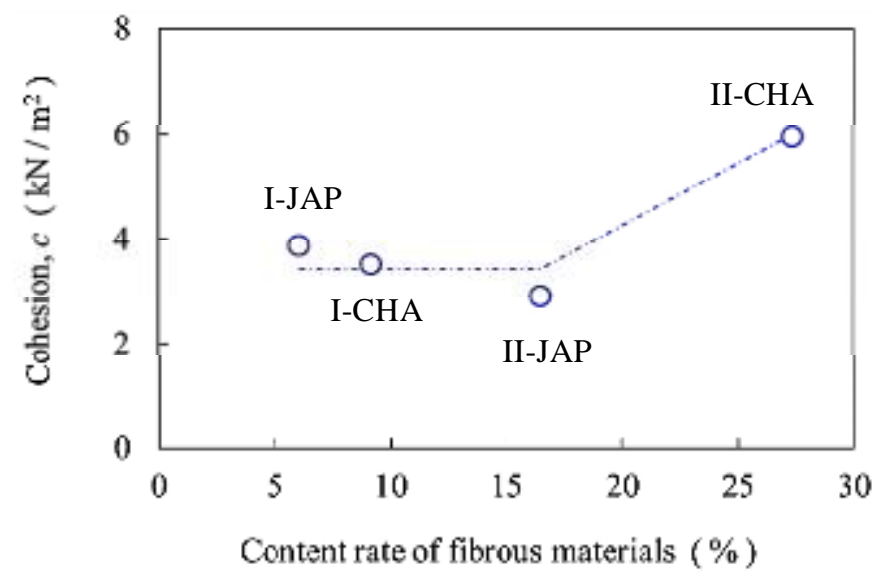

Figure 8. Change of cohesion with respect of fibrous materials content ratio for the four landfill sites.

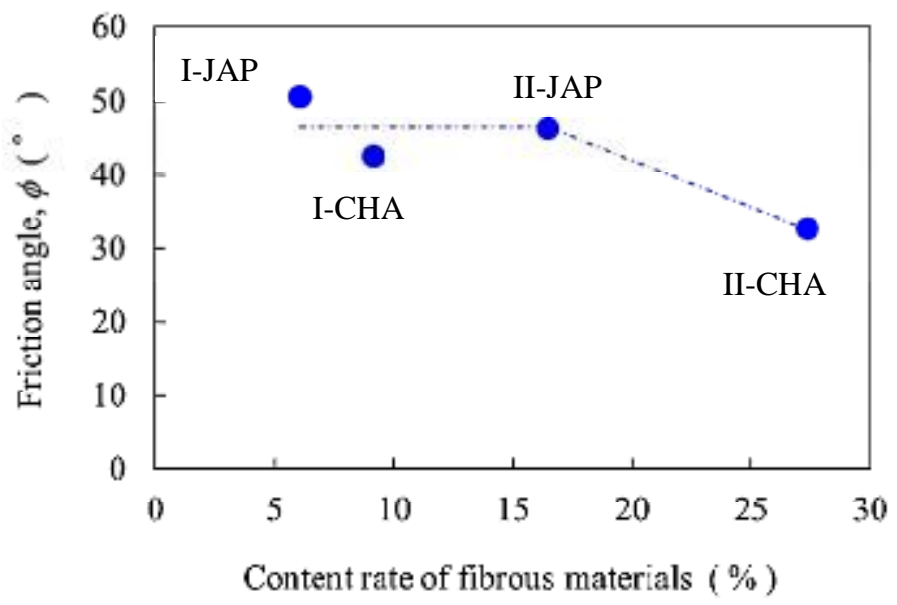

Figure 9. Change of internal friction angle with respect of fibrous materials content ratio for the four landfill sites.

\section{SUMMARY AND CONCLUSION}

In the present study, in-situ direct shear test apparatus was developed for testing of shear strength of municipal solid waste (MSW) materials. In-situ tests were conducted at four landfill sites that consist of different composition ratios of waste materials (two sites in Japan and two in China), and preparation procedures of undisturbed specimens for direct shear test were presented in details. The structure of MSW materials were essentially varied from site to site, hence, in order to provide insight regarding the real physical and mechanical properties of MSW, in-situ geotechnical tests were carried out. Moreover, relationships between in-situ shear response and composition ratio of waste materials were estimated. The main conclusions can be summarized as follows:

1. Shear response of municipal solid waste (MSW) materials is mainly depend on the amount of fibrous materials content when subjected to small deformation range. 
2. Elasticity property becomes prominent in large deformation ranges regardless of the amount of fibrous materials content due to stretching of fibrous materials with increasing shear displacement.

3. Shear response of waste materials exhibit ductility and elasticity characteristics de-pending on elongation of fibrous materials during shearing.

4. Cohesion of waste materials controls the shear behavior rather than the internal friction angle when the content ratio of fibrous materials are higher than $15 \%$.

\section{REFERENCES}

1. Bouzza, A., and Wojnarowicz, M. 2000. Stability Assessment of An Old Domestic Waste Slope in Warsaw (Po-land). Proc. Sessions of Geo-Denver, Denver, Colorado, pp. 48-57.

2. Dixon, N., Russell, D., and Jones, V., 2005. Engineering properties of municipal solid waste. Geotext. Geomembr. 23, pp. 205-233.

3. Hendron, D. M., Fernandez, G., Prommer, P. J., Giroud, J. P., and Orozco, L. F. 1999. Investigation of the cause of the 27 September 1997 slope failure at Dona Juana landfill. Proc. Sardinia.

4. Koerner, R. M., and T-Y. Soong. 2000. Stability Assessment of Ten Large Landfill Failures. Adv. In Transport. And Geoenviron. Systems Using Geosynthetics, pp. 1-38.

5. Jafari, N. H., Stark, T. D., and Merry, S. 2010. The 10 July 2000 Payatas landfill slope failure. International Journal of Geoengineering Case Histories, ISSMGE, Vol. X, Issue X, pp.1-21.

6. Japanese Geotechnical Society (JGS). Geotechnical and Geo-environmental Investigation Methods. Test Meth-od for Soil Density by the Compacted Sand Replacement Method. JGS 1611-2012.

7. Japanese Geotechnical Society (JGS). Laboratory Testing Standards of Geomaterials. Test Method for Water Content of Soils. JIS A 1203:2009.

8. Koelsch, F., Fricke, K., Mahler, C., and Damanhuri, E. 2005. Stability of landfills - The Bandung dumpsite disaster. Proceedings of the 10th International Landfill Symposium, Cagliari, Italy.

9. Machado, S.L., Karimpour-Fard, M., Shariatmadari, N., Carvalho, M.F., do Nascimento, J.C., 2010. Evaluation of the geotechnical properties of MSW in two Brazilian landfills. Waste Manage. 30 (12), 2579-2591.

10. Miyamoto, S., Yasufuku, N., Ishikura, R., Omine, K., Kawai, S., and Yamawaki, A. 2014. In-situ shearing response and shear strength of various solid waste ground focused on fibrous materials composition. Proceedings of the TC105 ISSMGE International Symposium on Geomechanics from Micro to Macro, IS-Cambridge 2014, Geomechanics from Micro to Macro - Soga et al. (Eds) 2015 Taylor \& Francis Group, London, ISBN 978-1-138-02707-7, pp. 1357- 1362.

11. Nejan, Huvaj-Sarihan and Timothy D. 2008. Back-Analyses of Landfill Slope Failures. 6th International Conference on Case Histories in Geotechnical Engineering. Paper No. 2.34 .

12. Reddy, K.R., Gangathulasi, J., Parakalla, N.S., Hettiarachchi, H., Bogner, J.E., Lagier, T., 2009. Compressibility and shear strength of municipal solid waste under short-term leachate recirculation operations. Waste Man-age. Res. 27 (6), pp. 578-587.

13. Towhata, I. and Uno, M. 2007. Laboratory Tests on Creep and Shear Behavior of Municipal Solid Waste and Mitigation of Its Long-Term Subsidence. Proc. GeoCongress 2008. New Orleans. pp.152-159.

14. Zekkos, D., Athanasopoulos, G. A., Bray, J. D., Grizi, A. and Theodoratos, A. 2010. Large-scale direct shear testing of municipal solid waste. Journal of Waste Management. Vol.30. pp.1544-1555.

15. Zhan, L.T., Chen, Y.M., and Ling, W.A., 2008. Shear strength characterization of municipal solid waste at the Suzhou landfill, China. Eng. Geol. 97, pp. 97-111. 